\title{
The effects of grain size and different multi-stage shearing techniques on shear strength along rock discontinuities
}

\author{
Alina Vattai ${ }^{1}$ - Nikoletta Rozgonyi-Boissinot ${ }^{1}$ \\ Received: 24 October 2019 / Accepted: 3 September 2020 / Published online: 6 October 2020 \\ (c) The Author(s) 2020
}

\begin{abstract}
The effects of grain size and different multi-stage shearing techniques on shear strength along discontinuities were analyzed in this study. Laboratory direct shear tests were carried out on plaster mortar with maximum grain sizes of $0.5 \mathrm{~mm}$ and $1.0 \mathrm{~mm}$. All specimen surfaces were essentially similar, copied from the same natural, Hungarian coarse-grained sandstone joint with a low joint roughness coefficient $($ JRC $=8)$. Tests within two different normal stress ranges $\left(\sigma_{\mathrm{n}}=0.25-0.5\right.$ and $\left.0.5-1.5 \mathrm{MPa}\right)$ were performed simultaneously. Specimens tested using the technique involving modified shearing with repositioning were sheared three times while being subjected to the same degree of normal stress ( shearing sequence $n=1,2,3$ ) and those with multi-stage technique without repositioning were subjected to shearing once at three different degrees of normal stress. The changing values of the peak friction angle calculated from the resulting peak shear strength-normal stress data pairs $\left(\tau_{p}-\sigma_{n}\right)$ were examined. Failure curves were estimated using linear regression, according to the Mohr-Coulomb failure criterion. The differences between the various peak friction angles obtained from experiments in which different multi-stage shearing techniques were used tend to increase in significance with the increasing number of shearing sequences. Peak friction angle values vary according to grain size of the material, though further investigations using more grain sizes are required to establish the extent of the effect on shear strength along discontinuities.
\end{abstract}

Keywords Shear strength of rock joints · Multi-stage direct shearing $\cdot$ Plaster mortar · Grain size

Mathematics Subject Classification 70-05 · 82-05 $\cdot$ 86A99

Alina Vattai

vattai.alina@gmail.com

1 Department of Engineering Geology and Geotechnics, Budapest University of Technology and Economics, Múegyetem rkp. 3, 1111 Budapest, Hungary 


\section{Abbreviations}

JCS Joint wall compressive strength

JMC Joint matching coefficient

JRC Joint roughness coefficient

\section{List of symbols}

A Total joint contact area

$\mathrm{A}_{0} \quad$ Maximum possible contact area

$\mathrm{a}_{\mathrm{j}} \quad$ Contact area of individual asperities

c Cohesion, apparent cohesion

C 3D roughness parameter

i Inclination angle of teeth

$i_{j} \quad$ Variable angle of asperities

$\beta \quad$ Angle between foliation plane and shearing direction

$\phi \quad$ Friction angle

$\phi_{\mathrm{b}} \quad$ Basic friction angle

$\phi_{\mathrm{r}} \quad$ Residual friction angle

$\sigma_{\mathrm{c}} \quad$ Uniaxial compressive strength of intact rock

$\sigma_{\mathrm{n}} \quad$ Normal stress

$\sigma_{\mathrm{nj}} \quad$ Normal stresses acting on the individual asperities

$\sigma_{t} \quad$ Brazilian tensile strength of intact rock

$\tau \quad$ Shear strength along discontinuity

$\tau_{\mathrm{p}} \quad$ Peak shear strength a.d

$\tau_{\mathrm{r}} \quad$ Residual shear strength a.d

$\Theta_{\mathrm{A}} \quad$ Average angle of asperities facing shear

$\Theta_{\max }$ Maximum asperity angle

$\Theta_{\max }^{*}$ Maximum apparent gradient of asperity along shear direction

\section{Introduction}

The failure of a rock slope or the rock environment of an engineering structure is usually not caused by the low quality of intact rock, but rather by fractures in the rock mass. Problems like the loss of rock slope or rock wall stability are generated by the exhaustion of shear strength along discontinuities. In addition, water flow or fluid flow in general may change along joints, cleavages or fractures (Köppel et al. 2019); or fluid flow may generate even new cracks (Mentes 2019). A number parameters of any rock joint can affect shear resistance to a great degree: water content, the filler material between the sides of a joint, exposure to weather (Barton 1973, 1976; Miščević and Vlastelica 2009), length of joint (Barton and Bandis 1982), surface roughness (Barton 1973; Haberfield and Seidel 1999; Grasselli and Egger 2003; Lee et al. 2014), the morphology of surface asperities (Patton 1966; Yang et al. 2016; Niktabar et al. 2017), the dilation angle (Barton 1973; Kumar and Verma 2016), the contact surface 
Fig. 1 Peak and residual shear strength on shear stress $\tau$ versus shear displacement $\Delta$ s diagram

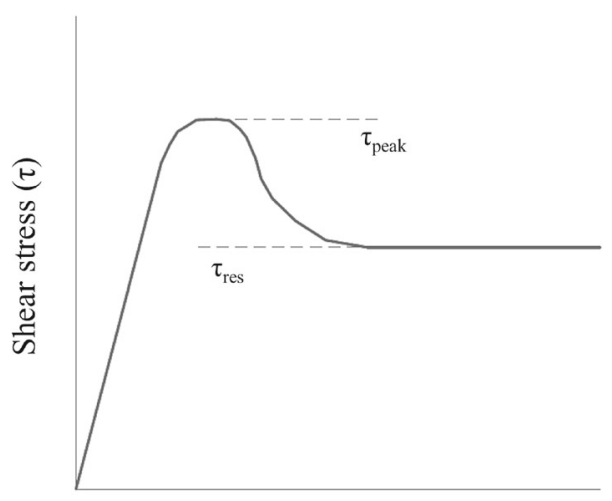

Shear displacement $(\Delta s)$

area (Zhao 1997; Grasselli and Egger 2003; Pirzada et al. 2020), inclination of the joint (Buocz et al. 2017), and the compressive strength of the joint (Barton 1973; Barton and Choubey 1977; Lee et al. 2014).

One of the most common ways to measure the shear strength of discontinuities, and analyze the influence of the parameters mentioned above, is the direct shear test, which can be performed in situ or in laboratory conditions. In situ tests can be carried out during the construction of structures such as a dam (Sanei et al. 2015), tunnel or waste repository, but in engineering practice shear strength is usually predicted in laboratory conditions, using shearing specimens with surfaces much smaller than the original discontinuities. Tests can be performed under constant normal load (CNL), which represents the failure mode of a slope, or constant normal stiffness (CNS), following the failure mode of a tunnel wall. Peak shear strength $\left(\tau_{p}\right)$, which is the highest recorded shear stress and after which shear load decreases, and residual shear strength $\left(\tau_{\text {rez }}\right)$, which is constant with increasing shear displacement, are obtained from a shear stress versus shear displacement diagram based on the results of the test (Fig. 1).

The final purpose of direct shear testing is to gain a failure curve based on shear strength-normal stress data pairs $(\tau-\sigma)$, which could then be used in the design of rock stability, as it shows the shear resistance of a rock joint in a given set of rock environmental stresses. To obtain the exact failure curve, as many $\tau-\sigma$ data pairs as possible need to be determined. A single sample is normally sheared once in one direction, but when it is not possible to obtain a sufficient number of specimens from the joint, it is possible to shear the same specimen repeatedly at different normal load stages with or without its replacement in its initial position between the stages (Muralha et al. 2015). With the help of this technique more points can be obtained on the $\tau-\sigma$ diagram.

Due to the inhomogeneity of a single joint, and because it is difficult to obtain a sufficient number of samples with similar qualities, the use of artificial rock specimens (plaster, cement mortar) with similar qualities to the original rock joints is common in research practice (Patton 1966; Grasselli and Egger 2003; Lee et al. 2014; Kumar and Verma 2016; Niktabar et al. 2017). In this way, tests are repeatable and it is possible to 
analyze the effect of a single property on shear strength by keeping the other effective parameters constant.

Measuring the uniaxial compressive strength of the intact rock $\left(\sigma_{c}\right)$ from rock mass surrounding the joint is highly recommended, since the condition of the rock environment can be estimated from its value, especially in the case of unweathered or slightly weathered rock mass, and it is very easy to measure compared to shear strength.

One of the basic failure criteria which can describe an empirical relationship between the shear strength and the examined parameter is the Mohr-Coulomb (M-C) form:

$$
\tau=\sigma_{n} * \tan \varphi+c
$$

where $\tau$ is shear strength, $\sigma_{\mathrm{n}}$ is normal stress, $\varphi$ is friction angle and $\mathrm{c}$ is cohesion, respectively. Over the last few decades, however, it has been observed that a nonlinear failure curve may well represent a better fit to experimental results than the linear M-C envelope. Many advanced non-linear failure criteria have been developed, modifying the $\mathrm{M}-\mathrm{C}$ form, as the effect of the parameters mentioned above on shear strength along discontinuities have been examined (Table 1). Patton (1966) created a bilinear model (2) which, though still linear, was not as simple as the basic form while examining the effect of the number and angle of asperities on specimens made of plaster of Paris under different constant normal load conditions. Barton (1973) developed one of the formulae most commonly used in practice (3) by examining surface morphological parameters over a wide range of loading conditions and on several types of unweathered natural rock joints; later, together with Choubey (Barton and Choubey 1977), this was then done on weathered natural rock joints (4). It was Barton, who created the concept of the joint roughness coefficient (JRC), which is capable of describing the magnitude of surface roughness with a maximum value of 20. Zhao (1997) adopted and modified the formula derived by Barton and Choubey (4) in the course of establishing the effects of matching area on granite rock joints under a maximum of $2.0 \mathrm{MPa}$ constant normal stress and thence derived an original Eq. (5) more suitable to use with empirical data. The criterion used by Grasselli and Egger (2003), in their study of surface morphology and matching area, resulted from shear tests at different values of constant normal stresses $\left(\sigma_{\mathrm{n}}=0.2-5.0 \mathrm{MPa}\right)$ on various natural soft and hard rock types with a wide range of compressive strength $\left(\sigma_{\mathrm{c}}=5-184 \mathrm{MPa}\right)$. In addition, artificial plaster material was also used $\left(\sigma_{\mathrm{c}}=46 \mathrm{MPa}\right)$. Their formula (7) is based on a highly comprehensive study, and represents a good fit to experimental data, but due to its complexity it is difficult to use in research practice. Yang et al. (2016) also performed several direct shear tests on granite and sandstone samples with high compressive strength $\left(\sigma_{\mathrm{c}}=65-161 \mathrm{MPa}\right)$ over a representative range of constant normal stresses $\left(\sigma_{\mathrm{n}}=0.325-8.0 \mathrm{MPa}\right)$. Their study focused on surface morphology, as seen in their non-linear Eq. (9). The failure criterion employed Lee et al. (2014) (8) is closer to Barton's (3) and focuses on the joint wall compressive strength measured on cement mortar replicas with high compressive strength $\left(\sigma_{\mathrm{c}}=54.19-83.91 \mathrm{MPa}\right)$. Kumar and Verma (2016) formed a criterion (10) by analyzing the way in which anisotropic shear 
behavior is influenced by surface morphology; the tests were conducted on cement mortar joint replicas $\left(\sigma_{\mathrm{c}}=40.83 \mathrm{MPa}\right)$ at $\sigma_{\mathrm{n}}=0.25-1.5 \mathrm{MPa}$.

Although many researchers have shown that a non-linear failure envelope is capable of reflecting real shearing behavior, in some cases linear forms do represent a valid approach. Haberfield and Seidel (1999) (Table 1) developed their failure criterion (6) on the basis of Patton's model as they studied the complex sliding behavior on artificial siltstone samples of low compressive strength $\left(\sigma_{\mathrm{c}}=3.5 \mathrm{MPa}\right)$ with regular and irregular asperities. Buocz et al. (2017) also adopted a bilinear criterion for the study of the effect of discontinuity inclination on Opalinus Claystone samples. Pirzada et al. (2020) applied an M-C failure criterion based on the results of different natural rock types with different normal strengths $\left(\sigma_{\mathrm{c}}=6.3-143.2 \mathrm{MPa}\right)$ and artificial rock samples $\left(\sigma_{\mathrm{c}}=27.0 \mathrm{MPa}\right)$. Tests were performed at $\sigma_{\mathrm{n}}=0.5-3.0 \mathrm{MPa}$. They found that, even in saturated conditions, the failure envelope can give a good fit to the experimental results by taking into account contact surface area of the joints.

In geotechnical engineering, the grain size of soil or other granular materials like sand has a great effect on shearing behavior. According to a study by Zelasko et al. (1975), in which three types of sand were investigated, increases in mean particle diameter can cause a decrease in the friction angle parameter. Some researchers, however, have observed the opposite phenomenon in the course of their investigations. Nakao and Fityus (2008), who studied coarse samples, have found that a higher friction angle resulted from samples with a higher grain diameter. The same tendency was observed by Wang et al. (2013), who investigated particle size distribution and the median value of grain diameter. The direct shear test results obtained by Islam et al. (2011) shows that both in cases of uniform particles (samples consisting of sand of uniform grain size) and in cases of graded particles (samples consisting of sand of different grain sizes) higher grain size causes a higher friction angle. Alias et al. (2014) reached the conclusion that peak and residual friction angles increase with increases in the grain size of granular materials. The shear resistance of a rock surface consists of the shear strength of the intact material and the frictional shear strength of the joint surface (Patton 1966). Although the mechanical shear behavior of soil or other granular materials in the geotechnical field more closely resembles the shear behavior of the intact rock, grain size may also have an effect on the shear resistance of a joint of compacted granular materials, such as sandstone.

Aim of this study is to investigate the effect of grain size on shear strength resulting from different multi-stage shearing techniques under constant normal stress. Direct shear tests were carried out under laboratory conditions under constant normal stress $\sigma_{\mathrm{n}}=0.25-1.5 \mathrm{MPa}$ to simulate the weight of a rock slope above a joint at shallow depth beneath the surface. In order to make the tests repeatable and eliminate the effects of different surface morphologies, specimens were made of plaster mortar with surfaces copied from the same natural sandstone joint with irregular asperities and low roughness $($ JRC $=8)$. Sand aggregates with a maximum grain diameter of 0.5 and $1.0 \mathrm{~mm}$ were chosen, as both are small enough to follow the original surface asperities adequately. As mentioned above, multi-stage direct shearing is allowable in the case of a small number of samples, but shearing with and without repositioning can result a somewhat different values for shear strength. In this study, multi-stage shearing tests without repositioning and modified multi-stage shearing tests with repositioning 


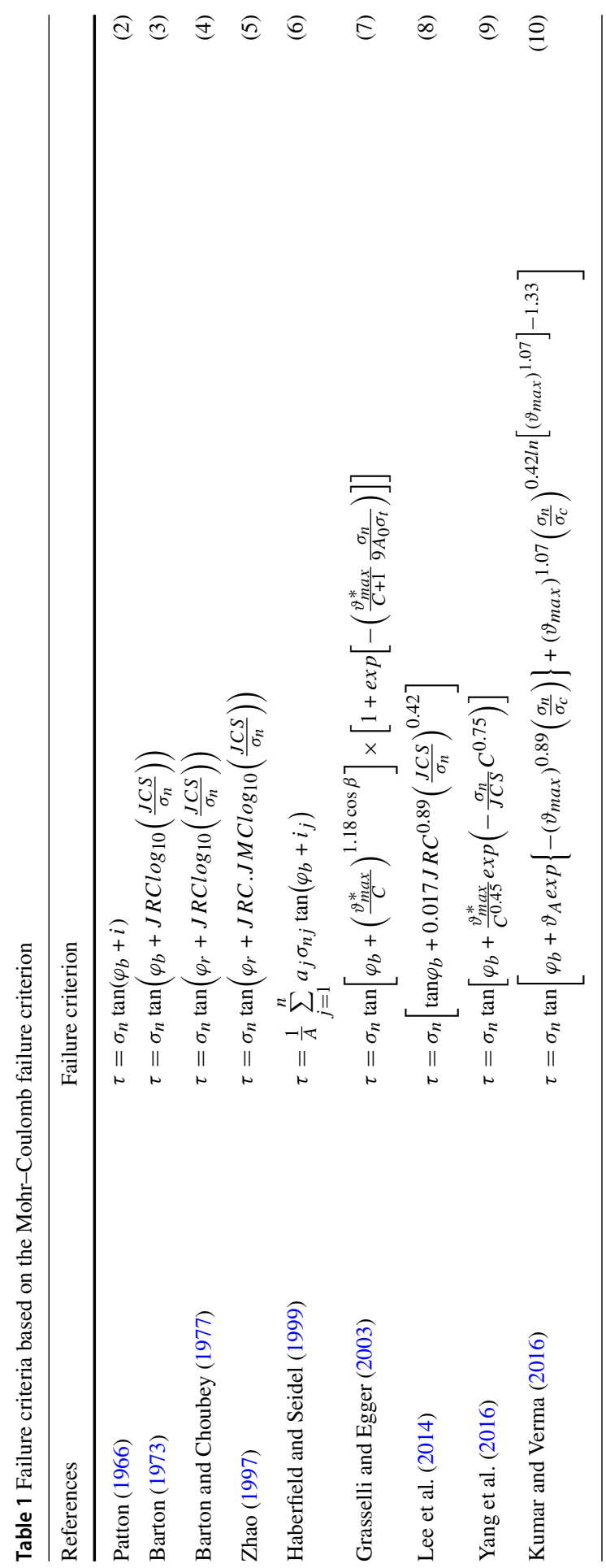


were carried out simultaneously. Since linear regression lines displayed a good fit to resulting peak shear strength-normal stress data pairs, the linear Mohr-Coulomb failure criterion was used in this study. The object of the examination was the changing of the peak friction angle derived from $\mathrm{M}-\mathrm{C}$ failure envelopes based on laboratory tests with different techniques at different constant normal stresses on specimens with different maximum grain sizes. The uniaxial compressive strengths of plaster types were measured simultaneously since this is one of the most important mechanical properties of the intact rock mass.

\section{Materials and methods}

\subsection{Materials and sample preparation}

In the interests of making laboratory tests repeatable, both sides of a natural Hungarian (Hárshegyi) sandstone joint were copied to surfaces of shearing specimens made of plaster mortar. There was no filler material between the two sides of the original rock joint, and the value of the joint roughness coefficient (JRC) of the section as measured by a Barton comb was 8 . Sand aggregates with a maximum diameter of $0.5 \mathrm{~mm}$ and $1.0 \mathrm{~mm}$ was used in the preparation of the specimens. One portion of plaster mortar mixture consisted of $40 \%$ sand aggregate, $40 \%$ high strength dental plaster powder and $20 \%$ water, and from this one shearing specimen with a rectangular surface size of $6540 \mathrm{~mm}^{2}$ and three cubes with size of $30 \times 30 \times 30 \mathrm{~mm}^{3}$ for uniaxial compressive tests were made. Before starting the shearing process, the upper and lower parts of shearing specimen were embedded separately in concrete in order to keep them fixed in the shear box during the test. The samples were kept and tested in air dry laboratory conditions after 28 days.

\subsection{Methods}

\subsubsection{Direct shear test}

In this study, in order to imitate the failure mode of a rock slope, direct shear tests under constant normal load (CNL) were performed using a manually operated CONTROLS D0548 direct shear machine in laboratory conditions. During the shearing process, the separate upper and lower parts of the specimen are put into the shearing equipment and pressed together at a constant value of normal load, and this is applied in the shear plane. The lower part of the shear box with the lower part of the specimen inside is fixed in all directions while the upper part of the box with the upper part of the specimen inside can move continuously parallel to the shear plane (Fig. 2).

Shear load, applied normal load, shear displacement and time are measured continuously (10 data/s) while the test is being conducted. Graphs of shear load and applied normal load via shear displacement are plotted. On the basis of suggestions made by the International Society of Rock Mechanics and Rock Engineering (ISRM), the test should be finished after the residual shear load is reached (curve becomes horizontal 


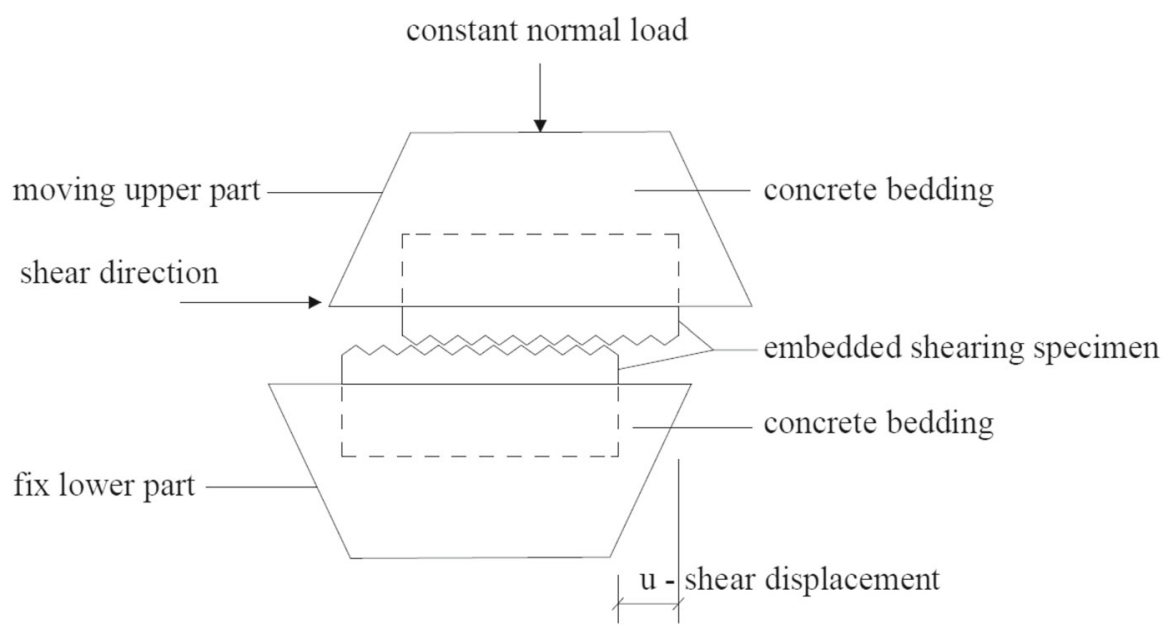

Fig. 2 Model of direct shearing

on shear load vs shear displacement diagram) or when shear displacement is about $10 \%$ of the specimen length (Muralha et al. 2015).

Usually a specimen is sheared only once under an applied normal load, but in cases when the number of specimens is inadequate, two types of multi-stage shearing procedures are used. In the first type of test, the same specimen is sheared repeatedly under increasingly higher normal loads, with the repositioning the specimen (joint) to its initial position before each shearing stage. In the other type of test, the specimen is sheared under increasingly higher normal loads, but it is not returned to its initial position between the shearing stages. Three, but preferably five stages are recommended in all types of test, and one stage is considered finished after residual shear load is reached. According to the ISRM suggestions low normal stresses should be used in the case of multi-stage shearing to minimize damage to surface asperities.

The purpose of this test is to obtain a value for peak shear strength $\left(\tau_{\mathrm{p}}\right)$ and residual shear strength $\left(\tau_{r}\right)$ as a function of applied normal stress $\left(\sigma_{n}\right)$ parameters which are calculated using peak shear load $\left(\mathrm{T}_{\mathrm{p}}\right)$, residual shear load $\left(\mathrm{T}_{\mathrm{r}}\right)$ and applied normal load $(\mathrm{N})$, respectively, divided by specimen surface area (A). On the basis of the Mohr-Coulomb failure criterion, the arctangent of the ratio of peak shear strength and the corresponding normal stress gives the peak friction angle, which is calculated from the envelope of linear regression; in this study, however, the term 'peak friction angle' $\left(\phi_{p}\right)$ is used to designate the inclination of a single $\tau_{p}-\sigma_{n}$ point, as seen in Fig. 3a, while for the peak friction angle of the failure curve, $\phi_{\text {pf }}$ is used (Fig. 3b).

In this study, changes in the peak friction angle based on shear test results of specimens with two different maximum grain sizes was examined. In cases where no peak shear strength appeared on the shear stress-normal stress graph, the maximum value of shear stress was in the place of peak shear strength (Fig. 4a, b). The shear displacement rate was about $0.5 \mathrm{~mm} / \mathrm{min}$. 

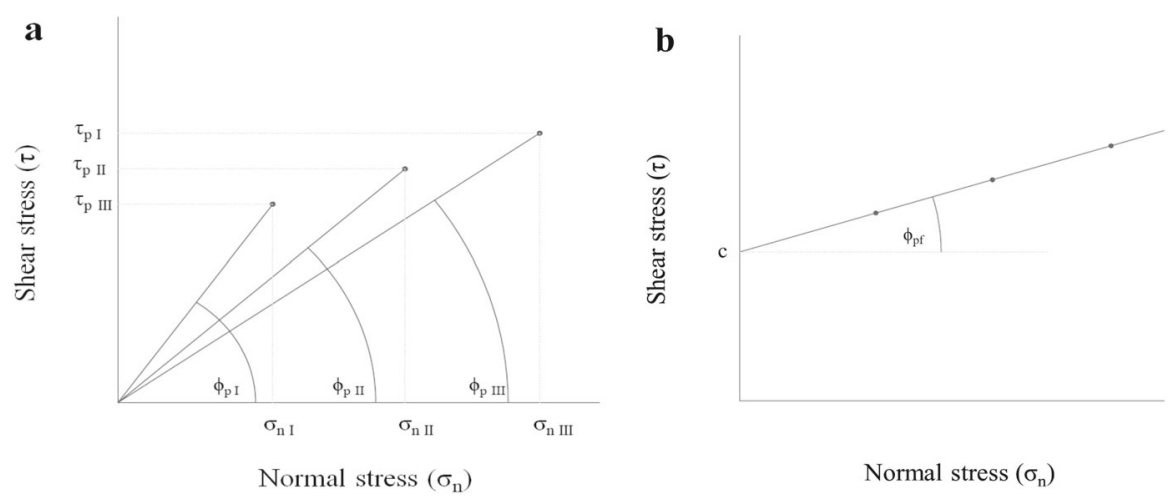

Fig. 3 Peak friction angle $\phi_{\mathrm{p}}$ on shear stress $\tau$ versus normal stress $\sigma_{\mathrm{n}}$ diagrams: $\phi_{\mathrm{p}}$ as the arctangent of the ratio of peak shear strength $\tau_{\mathrm{p}}$ and applied normal stress $\sigma_{\mathrm{n}}(\mathbf{a}) ; \phi_{\mathrm{pf}}$ as the slope of the curve of the Mohr-Coulomb failure criterion (b)
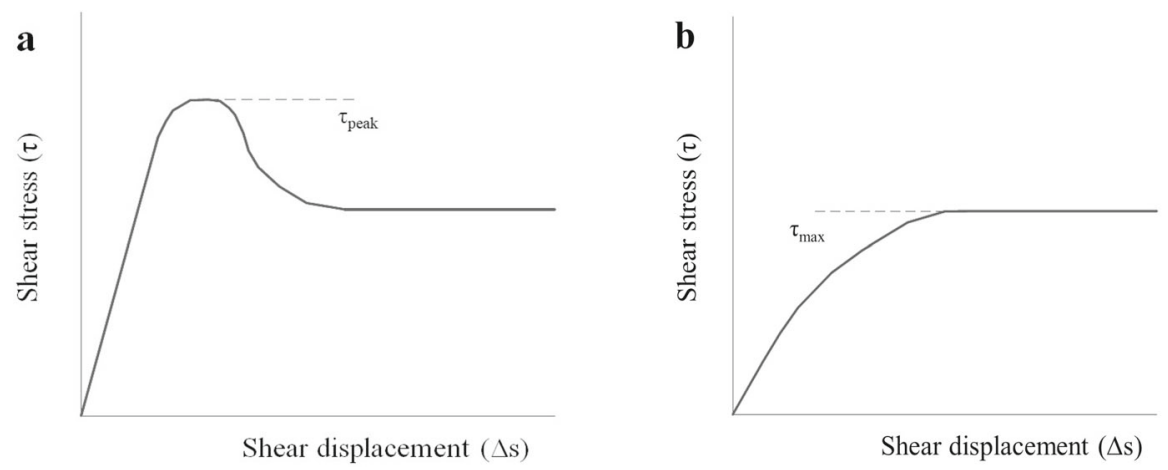

Fig. 4 Peak shear strength on shear stress $\tau$ versus shear displacement $\Delta$ s diagrams: as ' $\tau_{\text {peak }}$ ', after which shear stress decreases immediately (a); as ' $\tau_{\max }$ ', after which shear stress does not decrease immediately (b)

Multi-stage direct shear tests were carried out using two different techniques: (i) a multi-stage test without the repositioning of the samples between stages, (ii) a modified multi-stage test with the repositioning of the samples.

(i) In the first case, a single sample was sheared under low normal stresses (3 different stages: $0.25,0.375$ and $0.5 \mathrm{MPa}$ ), and another sample under higher applied normal stresses (3 different stages: 0.5, 1.0 and 1.5 MPa). Shear displacement was maximized at $5 \mathrm{~mm}$ in every normal stress stage, so the test was performed until $15 \mathrm{~mm}$ total displacement (18\% of the specimen length) had been achieved. A total of four specimens with two different maximum grain sizes was examined (Table 2). Peak friction angles based on failure curves $\left(\phi_{\mathrm{pf}}\right)$ from the 3 peak shear strength-normal stress data pairs resulting from tests were determined and compared in the cases of the two different maximum grain sizes.

(ii) In the second case, modified multi-stage tests with samples being repositioned between shearing stages, were performed. Each sample was sheared three times 


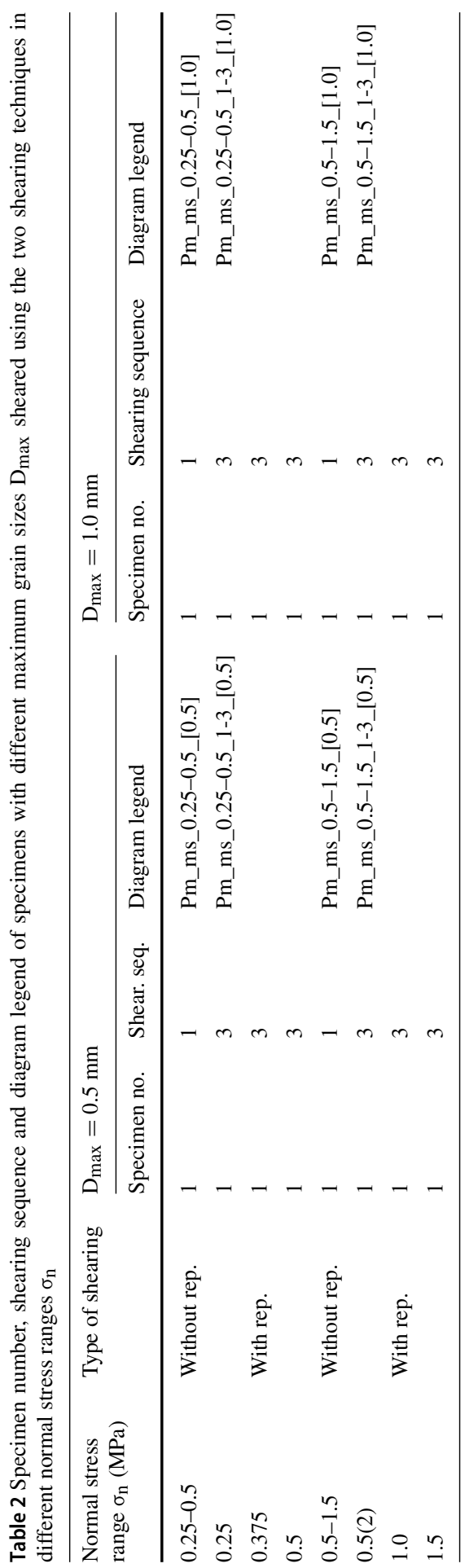


under the same applied normal stress, which means a shearing sequence of $\mathrm{n}=1,2$, 3. (In this case, 'modified' refers to the repeating of multi -stage shearing with repositioning, although shearing tests were performed three times at one stage per sample.) The aim of the modification is to analyze, to what extent the friction angle changes over the course of repeated shearing tests, and not necessarily under increasingly higher normal stresses, but even at the same level of normal stress. Tests were carried out at five different normal stresses $(0.25 ; 0.375 ; 0.5 ; 1.0 ; 1.5 \mathrm{MPa})$ in accordance with the first type of shearing test mentioned above, and on 12 samples with two different maximum grain sizes (Table 2).

The object of the investigation was changes in the peak friction angle $\left(\phi_{\mathrm{p}}\right)$ as the number of shearing sequences increases as a function of different normal loads and different maximum grain sizes. Furthermore, as was also the case in the first type of shearing, failure curves based on 3 peak shear strength-normal stress data pairs resulting from tests in low ranges of applied normal stress $(0.25 ; 0.375 ; 0.5 \mathrm{MPa})$, and in higher ranges of applied normal stress $(0.5 ; 1.0 ; 1.5 \mathrm{MPa})$ were determined in every shearing sequence. Changes in the peak friction angle on these curves $\left(\phi_{\mathrm{pf}}\right)$ by increasing the number of shearing sequences as a function of different normal stress ranges and different maximum grain sizes was also of interest. Finally, peak friction angles $\left(\phi_{\text {pf }}\right)$ belonging to these curves and to curves based on data pairs from tests without repositioning were compared, taking into consideration the different normal stress ranges and different maximum grain sizes.

\subsubsection{Uniaxial compressive test}

Parallel to this shearing, uniaxial compressive tests were performed on three plaster cubes pertaining to each shearing specimen. In the course of the test, a cube is placed between two parallel platens, of which the upper is fixed, while the lower elevates the specimen right up to the point of failure due to the compression. The speed of compression and vertical (axial) load are measured continuously. Uniaxial compressive strength (UCS) is equal to the ratio of the collapsing compressive force $\left(\mathrm{F}_{\mathrm{c}}\right)$ and compressed area (A). In this study, the speed of compression was $0.9 \mathrm{kN} / \mathrm{s}$. The average UCS values of the three cubes pertaining to each shearing specimen are in Table 3.

\section{Results and discussion}

(1) Peak shear strength $\left(\tau_{p}\right)$-applied normal stress $\left(\sigma_{n}\right)$ data pairs based on multistage shear tests without repositioning, peak friction angle $\left(\phi_{\mathrm{pf}}\right)$ and apparent cohesion (c) as the parameters of Mohr-Coulomb failure curves calculated from these data pairs are represented in Table 4, presenting in terms of normal stress range and maximum grain size $\left(D_{\max }\right)$. The failure curves calculated from these $\tau_{p}-\sigma_{n}$ data pairs using linear regression, the equations of the linear regression as a failure criterion, the regression coefficient $\mathrm{r}^{2}$ values and calculated peak friction angle in the normal stress range of $0.25-0.375-0.5 \mathrm{MPa}$ are shown in Fig. 5a, and the results in the normal stress range of $0.5-1.0-1.5 \mathrm{MPa}$ in Fig. 5b. 
Table 3 Uniaxial compressive strength (UCS) of specimens with different maximum grain sizes $\mathrm{D}_{\max }$ sheared using the two shearing techniques in different normal stress ranges $\sigma_{\mathrm{n}}$

\begin{tabular}{llll}
\hline Normal stress range $\sigma_{\mathrm{n}}(\mathrm{MPa})$ & Type of shearing & \multicolumn{2}{l}{ Uniaxial compressive strength $(\mathrm{MPa})$} \\
\cline { 3 - 4 } & & $\mathrm{D}_{\max }=0.5 \mathrm{~mm}$ & $\mathrm{D}_{\max }=1.0 \mathrm{~mm}$ \\
\hline $0.25-0.5$ & Without rep. & 24.31 & 19.82 \\
0.25 & With rep. & 22.06 & 19.53 \\
0.375 & & 26.84 & 21.5 \\
0.5 & & 24.62 & 24.15 \\
$0.5-1.5$ & Without rep. & 16.04 & 18.84 \\
$0.5(2)$ & With rep. & 20.43 & 19.45 \\
1.0 & & 21.39 & 20.28 \\
1.5 & & 16.66 & 19.74 \\
\hline
\end{tabular}

Table 4 Mohr-Coulomb failure criterion parameters peak friction angle $\phi_{\text {pf }}$ and apparent cohesion c based on peak shear strength $\tau_{\mathrm{p}}$-applied normal stress $\sigma_{\mathrm{n}}$ data pairs resulting from direct shearing without repositioning. Shear tests were carried out in different normal stress ranges on specimens with different maximum grain sizes $\mathrm{D}_{\max }$

\begin{tabular}{|c|c|c|c|c|c|c|c|c|}
\hline \multirow{2}{*}{$\begin{array}{l}\text { Normal stress } \\
\text { range (MPa) }\end{array}$} & \multicolumn{4}{|c|}{$\mathrm{D}_{\max }=0.5 \mathrm{~mm}$} & \multicolumn{4}{|c|}{$\mathrm{D}_{\max }=1.0 \mathrm{~mm}$} \\
\hline & $\tau_{\mathrm{p}}(\mathrm{MPa})$ & $\sigma_{\mathrm{n}}(\mathrm{MPa})$ & $\phi_{\mathrm{pf}}\left({ }^{\circ}\right)$ & $\mathrm{c}(\mathrm{MPa})$ & $\tau_{\mathrm{p}}(\mathrm{MPa})$ & $\sigma_{\mathrm{n}}(\mathrm{MPa})$ & $\phi_{\mathrm{pf}}\left({ }^{\circ}\right)$ & $\mathrm{c}(\mathrm{MPa})$ \\
\hline \multirow[t]{3}{*}{$0.25-0.5$} & 0.138 & 0.242 & 45.6 & 0.000 & 0.217 & 0.258 & 47.7 & 0.000 \\
\hline & 0.258 & 0.346 & & & 0.295 & 0.379 & & \\
\hline & 0.416 & 0.473 & & & 0.435 & 0.505 & & \\
\hline \multirow[t]{3}{*}{$0.5-1.5$} & 0.424 & 0.464 & 36.5 & 0.111 & 0.349 & 0.506 & 43.9 & 0.000 \\
\hline & 0.661 & 0.916 & & & 0.744 & 0.993 & & \\
\hline & 1.007 & 1.380 & & & 1.179 & 1.500 & & \\
\hline
\end{tabular}

The minimum value of $\mathrm{r}^{2}$ is 0.875 , except in one of the four groups $\left(D_{\max }=0.5 \mathrm{~mm} ; \sigma_{\mathrm{n}}=0.5-1.5 \mathrm{MPa}\right)$, and $*$ indicates significance levels of $p \leq 0.1$. As in the experiments of Nakao and Fityus (2008), Islam et al. (2011) and Alias et al. (2014) in lower (Fig. 5a) and also higher ranges of normal stress (Fig. 5b), peak friction angle values associated with $\mathrm{D}_{\max }=1.0$ are higher than those associated with $\mathrm{D}_{\max }=0.5 \mathrm{~mm}$ (at the values of $4.6 \%$ and $20.3 \%$, respectively). As in the experiments of Buocz et al. (2017), the M-C linear failure criterion displays a good fit to these experimental data pairs, the peak friction angle values based on tests with $\mathrm{D}_{\max }=0.5$ and also those based on tests with $\mathrm{D}_{\max }=1.0 \mathrm{~mm}$ (Table 4) are, however, lower in the higher normal stress range than corresponding values in the lower normal stress range $(24.9 \%$ and $8.7 \%$, respectively).

(2) Peak shear strength $\left(\tau_{p}\right)$-applied normal stress $\left(\sigma_{n}\right)$ data pairs yielded by modified multi-stage shear tests with repositioning and the corresponding peak friction angle $\left(\phi_{\mathrm{p}}\right)$ in each three shearing sequence; peak friction angle values in each shearing sequence $(\mathrm{n}=1,2,3)$ compared to the friction angle of the first test 


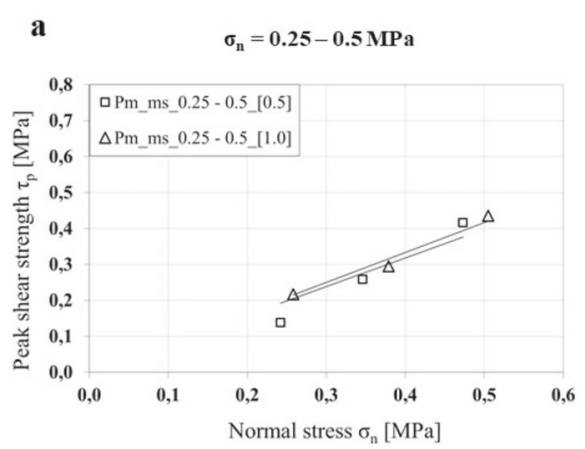

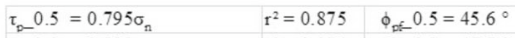

$\tau_{\mathrm{D}-1.0}=0.833 \sigma_{\mathrm{n}} \quad \mathrm{r}^{2}=0.974 \quad \oint_{\mathrm{p}-1.0} 1.047 .7^{\circ}$ b

$\sigma_{\mathrm{n}}=0.5-1.5 \mathrm{MPa}$

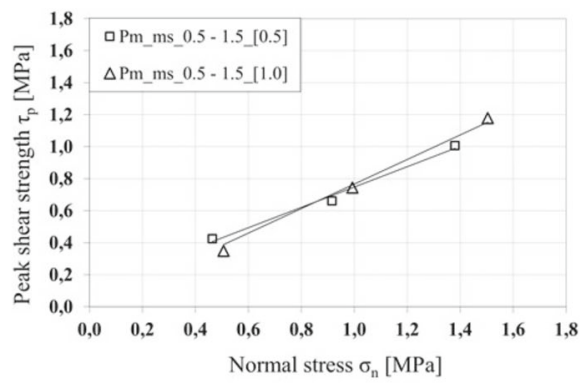

$\tau_{\mathrm{D}-} 0.5=0.637 \sigma_{\mathrm{n}}+0.111 \quad \mathrm{r}^{2}=0.990^{*} \quad \phi_{\mathrm{Df}} 0.5=36.5^{\circ}$ $\begin{array}{lll}\tau_{\mathrm{D}-} 1.0=0.767 \sigma_{\mathrm{n}} & \mathrm{r}^{2}=0.993^{*} & \phi_{\mathrm{Df}-1} 1.0=43.9^{\circ}\end{array}$

Fig. 5 Curves of the Mohr-Coulomb failure criterion on peak shear strength $\tau_{\mathrm{p}}$ versus normal stress $\sigma_{\mathrm{n}}$ diagrams resulting from direct shearing without repositioning (Pm_ms) in a lower normal stress range $\sigma_{\mathrm{n}}$ (a) and in a higher normal stress range $\sigma_{\mathrm{n}}$ (b) with the formulae of failure criterion, values of correlation coefficient $\mathrm{r}^{2}$ and peak friction angle $\phi_{\mathrm{pf}}$ beneath the diagrams. In both normal stress ranges shear tests were carried out on plaster mortar specimens with different maximum grain sizes: $\mathrm{D}_{\max }=0.5 \mathrm{~mm}[0.5]$ and $1.0 \mathrm{~mm}[1.0]$

$\left(\phi_{\mathrm{pn}} / \phi_{\mathrm{p} 1}\right)$; and the maximal value of the friction angle differences $\left(\left(\Delta \phi_{\mathrm{p}}\right)_{\max }\right)$ calculated from $\phi_{\mathrm{pn}}$ minus $\phi_{\mathrm{p} 1}$ are presented in Table 5. When the friction angle resulting from repeated shearing $\left(\phi_{\mathrm{pn}}\right)$ is higher than friction angle of the first shearing $\left(\Delta \phi_{\mathrm{p}}\right)_{\max }$, the parameter is positive; otherwise it is negative. All results are grouped according to the five different applied normal stresses $\left(\sigma_{\mathrm{n}}=0.25-1.5 \mathrm{MPa}\right)$ and two different maximum grain sizes $\left(\mathrm{D}_{\max }=0.5 \mathrm{~mm} ; 1.0 \mathrm{~mm}\right)$.

The values of the $\phi_{\mathrm{pn}}: \phi_{\mathrm{p} 1}$ ratio in the first tests never fall between the corresponding values of the second and the third tests, so results based on repeated shearing may be either higher or lower than the first results. It has to be noted, however, that only in three of the 12 cases, did the ratio increase continuously $\left(D_{\max }=0.5 \mathrm{~mm}\right.$, $\sigma_{\mathrm{n}}=0.5$ and $1.0 \mathrm{MPa} ; \mathrm{D}_{\max }=1.0 \mathrm{~mm}, \sigma_{\mathrm{n}}=1.5 \mathrm{MPa}$ ) and only in one case does it decrease continuously $\left(\mathrm{D}_{\max }=1.0 \mathrm{~mm}, \sigma_{\mathrm{n}}=1.0 \mathrm{MPa}\right)$ with the increasing number of shearing sequences. The values of $\left(\Delta \phi_{\mathrm{p}}\right)_{\max }$ are positive in half of the six cases $\left(\sigma_{\mathrm{n}}=0.25,0.5,1.5 \mathrm{MPa}\right)$, with $\mathrm{D}_{\max }=0.5 \mathrm{~mm}$, as are those with a value for $D_{\max }=1.0 \mathrm{~mm}$ in four from the six cases $\left(\sigma_{\mathrm{n}}=0.25,0.5,0.5(2), 1.5 \mathrm{MPa}\right)$. Furthermore, the maximum value of any decrease is $9-13 \%\left(D_{\max }=0.5 \mathrm{~mm}\right)$ and $7-12 \%\left(D_{\max }=1.0 \mathrm{~mm}\right)$, while the maximum increases are $20-46 \%$ and $8-83 \%$, respectively. Though it has to be noted that if a positive difference of $83 \%$ is regarded as an exception, the maximum increase is only in the range of $8-19 \%$.

(3) Peak friction angle ( $\left.\phi_{\mathrm{pf}}\right)$ and apparent cohesion (c) as the parameters of MohrCoulomb failure curves based on the results of modified multi-stage shear tests with repositioning are shown in Table 6. Curves of the shearing sequences are calculated from peak shear strength $\left(\tau_{\mathrm{p}}\right)$-applied normal stress $\left(\sigma_{\mathrm{n}}\right)$ data pairs in the same sequences. Furthermore, the table shows the peak friction angle values in each shearing sequence $(\mathrm{n}=1,2,3)$ compared to the friction angle of the 


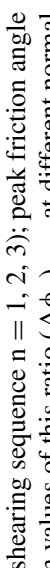

$\mid$

䒕

i

II ¿

\&

急

感

隹管

$\frac{\sqrt{n}}{3}$

唯

: ڤ્ּ

웡

을

$3 \dot{2}$

藏

कै

ठ욜

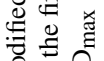

을

产常.

on

寻

吅 园

$\infty \quad \frac{1}{1}$

9

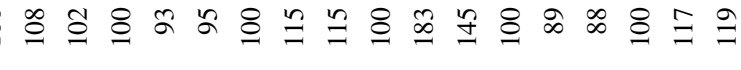

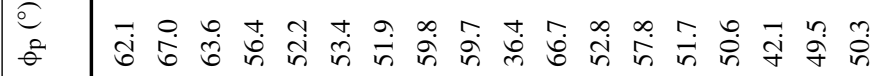

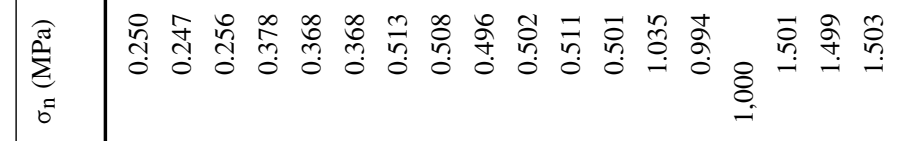

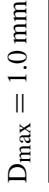

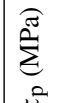

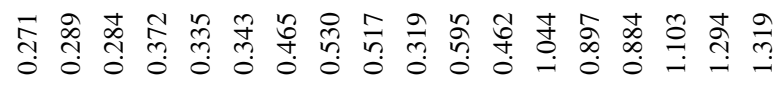

$-a m-c m-n m-n m-n-4 m$

o

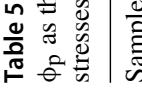

กั่

$\stackrel{\substack{n \\ \hdashline}}{3}$

?

ปู

$\stackrel{\circ}{\circ}$

? 
Table $6 \mathrm{Mohr}-$ Coulomb linear failure criterion parameters peak friction angle $\phi_{\mathrm{pf}}$ and apparent cohesion $\mathrm{c}$, based on peak shear strength-applied normal stress data pairs resulting from modified shear tests with repositioning (shearing sequence $\mathrm{n}=1,2,3$ ); ratio of peak friction angle of repeated shearing tests $\phi_{\text {pfn }}$ to that of the first test $\phi_{\mathrm{pf} 1}$; and the change in this ratio $\Delta \phi_{\mathrm{pf}}$. Tests were carried out in different applied normal stress ranges, on specimens with different maximum grain sizes $\mathrm{D}_{\max }$

\begin{tabular}{|c|c|c|c|c|c|c|c|c|c|c|}
\hline \multirow{2}{*}{$\begin{array}{l}\text { Normal } \\
\text { stress } \\
\text { range } \\
(\mathrm{MPa})\end{array}$} & \multicolumn{5}{|c|}{$\mathrm{D}_{\max }=0.5 \mathrm{~mm}$} & \multicolumn{5}{|c|}{$\mathrm{D}_{\max }=1.0 \mathrm{~mm}$} \\
\hline & $\begin{array}{l}\text { Sh } \\
\text { sec }\end{array}$ & $\begin{array}{l}\mathrm{c} \\
(\mathrm{MPa})\end{array}$ & $\phi_{\mathrm{pf}}\left(^{\circ}\right)$ & $\begin{array}{l}\phi_{\mathrm{pfn}} \\
(\%)\end{array}$ & $\begin{array}{c}1 \stackrel{\Delta \phi_{\mathrm{pf}}}{(\%)} \\
(\%)\end{array}$ & $\begin{array}{l}\text { Sh } \\
\text { sec }\end{array}$ & $\begin{array}{l}\mathrm{c} \\
(\mathrm{MPa})\end{array}$ & $\phi_{\mathrm{pf}}\left(^{\circ}\right)$ & $\begin{array}{l}\phi_{\mathrm{pfn}} \\
(\%)\end{array}$ & $\begin{array}{c}1 \phi_{\mathrm{pf}} \\
(\%)\end{array}$ \\
\hline \multirow[t]{3}{*}{$0.25-0.5$} & 1 & 0.059 & 42.8 & 100 & 0 & 1 & 0.089 & 42.2 & 100 & 0 \\
\hline & 2 & 0.023 & 52.4 & 122 & 22 & 2 & 0.034 & 53.6 & 127 & 27 \\
\hline & 3 & 0.000 & 61.4 & 143 & 43 & 3 & 0.015 & 56.1 & 133 & 33 \\
\hline \multirow[t]{3}{*}{$0.5-1.5$} & 1 & 0.208 & 41.0 & 100 & 0 & 1 & 0.013 & 45.7 & 100 & 0 \\
\hline & 2 & 0.004 & 52.5 & 128 & 28 & 2 & 0.220 & 40.6 & 89 & -11 \\
\hline & 3 & 0.000 & 55.4 & 135 & 35 & 3 & 0.032 & 49.0 & 107 & 7 \\
\hline
\end{tabular}

first sequence $\left(\phi_{\mathrm{p} 1}\right)$, and the value of friction angle differences $\left(\Delta \phi_{\mathrm{pf}}\right)$ calculated from $\phi_{\mathrm{pfn}}$ minus $\phi_{\mathrm{p} 1}$. When the friction angle resulting from repeated shearing tests $\left(\phi_{\text {pfn }}\right)$ is higher than the friction angle obtained in the first shearing tests, the parameter $\Delta \phi_{\mathrm{pf}}$ is positive; otherwise it is negative. All results are grouped according to the two different applied normal ranges $\left(\sigma_{\mathrm{n}}=0.25-0.5 \mathrm{MPa}\right.$; $0.5-1.5 \mathrm{MPa})$ and two different maximum grain sizes $\left(\mathrm{D}_{\max }=0.5 \mathrm{~mm} ; 1.0 \mathrm{~mm}\right)$. Figure 6a presents in graphic form failure curves from Table 6 in each shearing sequence based at tests performed at $\sigma_{\mathrm{n}}=0.25-0.5 \mathrm{MPa}$ with $\mathrm{D}_{\max }=0.5 \mathrm{~mm}$, together with the failure curves from tests without repositioning under the same range of normal stress, and with the same maximum grain size. The equations of linear regression, the regression coefficient $r^{2}$ values, and calculated peak friction angles are also shown in the figure. The same parameters of tests carried out at $\sigma_{\mathrm{n}}=0.25-0.5 \mathrm{MPa}$ with $\mathrm{D}_{\max }=0.5 \mathrm{~mm}$; at $\sigma_{\mathrm{n}}=0.25-0.5 \mathrm{MPa}$ with $\mathrm{D}_{\max }=1.0 \mathrm{~mm}$; at $\sigma_{\mathrm{n}}=0.5-1.5 \mathrm{MPa}$ with $\mathrm{D}_{\max }=0.5 \mathrm{~mm}$ and at $\sigma_{\mathrm{n}}=0.5-1.5 \mathrm{MPa}$ with $\mathrm{D}_{\max }=1.0 \mathrm{~mm}$, are shown in Fig. $6 \mathrm{~b}-\mathrm{d}$, respectively. Peak friction angle $\left(\phi_{\mathrm{pf}}\right)$ and apparent cohesion (c) as the parameters of MohrCoulomb failure curves based on the results of modified multi-stage shear tests with repositioning are presented in Table 7 . The curves of the shearing sequences are calculated from peak shear strength $\left(\tau_{\mathrm{p}}\right)$-applied normal stress $\left(\sigma_{\mathrm{n}}\right)$ data pairs in the same sequences. Parameters yielded by multi-stage shearing tests without repositioning are also to be found in Table 7 . All results are grouped according to the two different applied normal stress ranges $\left(\sigma_{\mathrm{n}}=0.25-0.5 \mathrm{MPa} ; 0.5-1.5 \mathrm{MPa}\right)$ and two different maximum grain sizes $\left(\mathrm{D}_{\max }=0.5 \mathrm{~mm}: 1.0 \mathrm{~mm}\right)$. Furthermore, the table also shows peak friction angle values in each shearing sequence $(\mathrm{n}=$ $1,2,3)$ compared to the friction angle resulting from tests without repositioning $\left(\phi_{\mathrm{pfI}}\right)$, and the value of friction angle differences $\left(\Delta \phi_{\mathrm{pf}}\right)$ calculated from $\phi_{\mathrm{pfn}}$ minus $\phi_{\text {pfI }}$.

Focusing on the differences between the results of tests with repositioning, the values of $\phi_{\text {pf }}$ increase with an increasing number of shearing sequences, with 


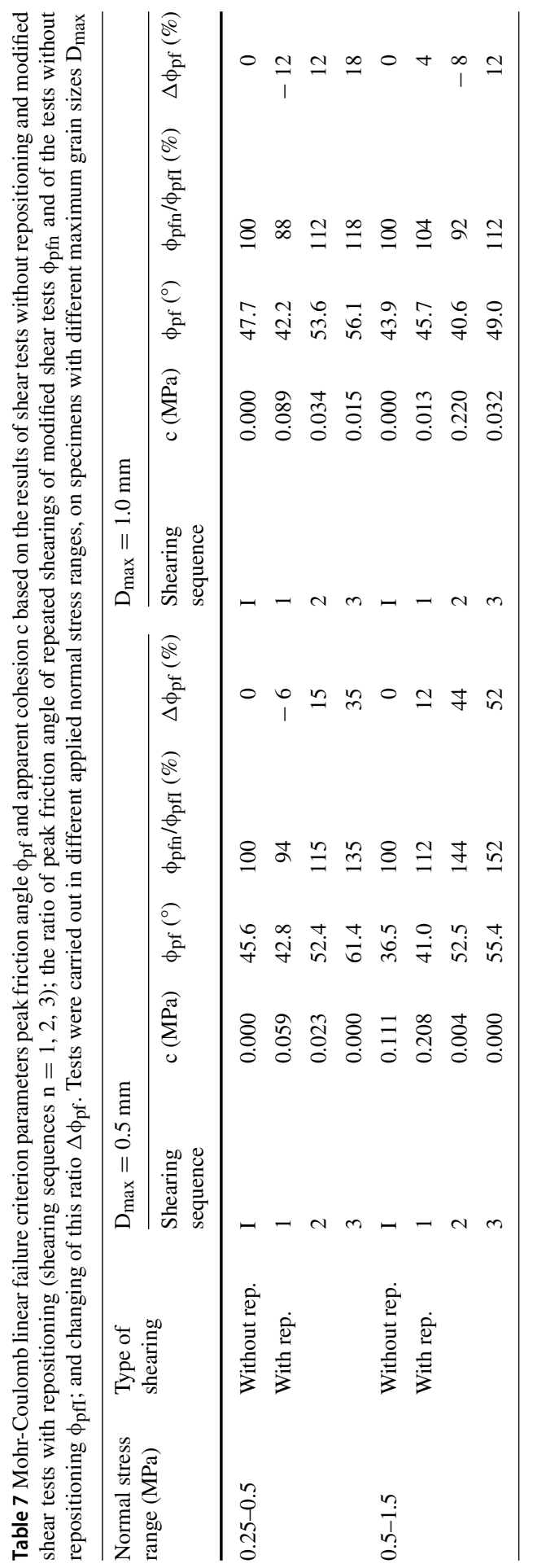


$\mathbf{a}$

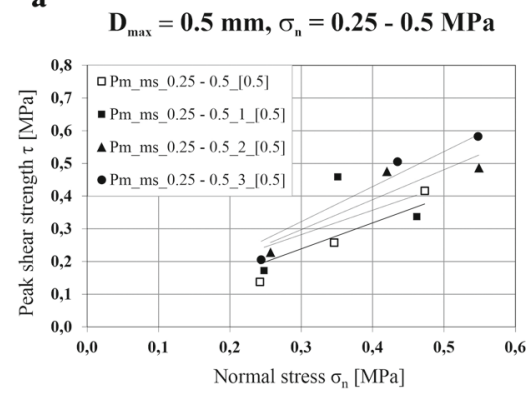

b

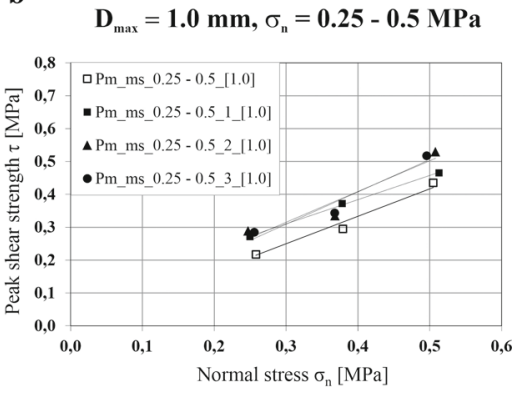

c

$$
\mathrm{D}_{\max }=0.5 \mathrm{~mm}, \sigma_{\mathrm{n}}=0.5-1.5 \mathrm{MPa}
$$

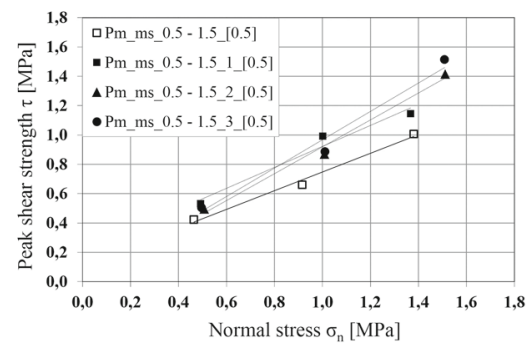

$$
\begin{array}{lll|}
\tau_{\mathrm{p} \_} 0.5=0.637 \sigma_{\mathrm{n}}+0.111 & \mathrm{r}^{2}=0.990^{*} & \phi_{\mathrm{p} \complement} 0.5=36.5^{\circ} \\
\tau_{\mathrm{p} \_} 0.5 \_1=0.715 \sigma_{\mathrm{n}}+0.208 & \mathrm{r}^{2}=0.965 & \phi_{\mathrm{p} \_} 0.5 \_1=41.0^{\circ} \\
\tau_{\mathrm{p} \_} 0.5 \_2=0.916 \sigma_{\mathrm{n}}+0.004 & \mathrm{r}^{2}=0.989^{*} & \phi_{\mathrm{p \complement}} 0.5 \_2=52.5^{\circ} \\
\tau_{\mathrm{p} \_} 0.5 \_3=0.967 \sigma_{\mathrm{n}} & \mathrm{r}^{2}=0.977^{*} & \phi_{\mathrm{pf} \_} 0.5 \_3=55.4^{\circ}
\end{array}
$$

d

$$
\mathrm{D}_{\max }=1.0 \mathrm{~mm}, \sigma_{\mathrm{n}}=0.5-1.5 \mathrm{MPa}
$$

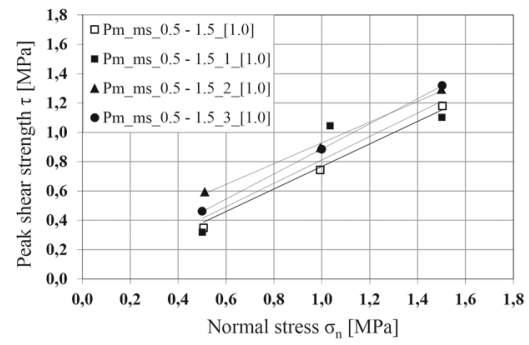

$$
\begin{aligned}
& \tau_{\mathrm{p} \_} 1.0=0.767 \sigma_{\mathrm{n}} \quad \mathrm{r}^{2}=0.993^{*} \quad \phi_{\mathrm{pf} \_} 1.0=43.9^{\circ} \\
& \tau_{\mathrm{p} \_} 1.0 \_1=0.798 \sigma_{\mathrm{n}}+0.013 \quad \mathrm{r}^{2}=0.836 \quad \phi_{\mathrm{pf} \_} 1.0 \_1=45.7^{\circ} \\
& \tau_{\mathrm{p} \_} 1.0 \_2=0.708 \sigma_{\mathrm{n}}+0.220 \quad \mathrm{r}^{2}=0.996^{* *} \phi_{\mathrm{pf} \_} 1.0 \_2=40.6^{\circ} \\
& \tau_{\mathrm{p} \_} 1.0 \_3=0.855 \sigma_{\mathrm{n}}+0.032 \mathrm{r}^{2}=1.000^{* *} \phi_{\mathrm{pf} \_} 1.0 \_3=49.0^{\circ}
\end{aligned}
$$

Fig. 6 Curves of the Mohr-Coulomb failure criterion on peak shear stress $\tau_{p}$ versus normal stress $\sigma_{n}$ diagrams resulting from direct shearing without repositioning $\left(\mathrm{Pm} \_\mathrm{ms}\right)$ and from modified direct shearing with repositioning (Pm_ms_1,2,3) in a lower normal stress range $\sigma_{\mathrm{n}}(\mathbf{a}, \mathbf{b})$ and higher normal stress range $\sigma_{\mathrm{n}}(\mathbf{c}$, d). Formulae of the failure criterion, the values of correlation coefficient $r^{2}$ and peak friction angle $\phi_{\mathrm{pf}}$ are beneath the diagrams. In both normal stress ranges shear tests were carried out on plaster mortar specimens with different maximum grain sizes: $\mathrm{D}_{\max }=0.5 \mathrm{~mm}[0.5](\mathbf{a}, \mathbf{c})$ and $1.0 \mathrm{~mm}[1.0](\mathbf{b}, \mathbf{d})$

the exception of one of the four groups $\left(D_{\max }=1.0 \mathrm{~mm}: \sigma_{\mathrm{n}}=0.5-1.5 \mathrm{MPa}\right)$ (Table 6). The values of the second sequences are 22-28\% higher than those of the first tests while in the exceptional group, $\phi_{\mathrm{pf}}$ is $11 \%$ lower. The values of third sequences are the highest in all groups, with differences of 33-43\%, while in the exceptional group, this is $7 \%$. The values of apparent cohesion decrease as the corresponding friction angles increase. The value of $\mathrm{r}^{2}$ is at least 0.835 , except in one case $\left(D_{\max }=0.5 \mathrm{~mm}: \sigma_{\mathrm{n}}=0.25-0.5 \mathrm{MPa}, 1\right.$. shearing sequence $)$ as can be seen in Fig. 6a-d, in which $*$ and $* *$ indicate significance levels of $p \leq 0.1$ 
and 0.05 , respectively. The differences between corresponding values of friction angle and cohesion are not significant in the low normal stress range by increasing number of shearing sequences, for either of the grain sizes (Table 6). In the higher normal stress range, however, trends in the change of friction angle and cohesion with an increasing number of shearing sequences are not similar in the cases of different grain sizes. In the case of $\mathrm{D}_{\max }=0.5 \mathrm{~mm}$, the values of the friction angle in a lower normal stress range are similar to the corresponding values in the higher stress range, though the differences between the corresponding cohesion values are significant within the different ranges. In case of $\mathrm{D}_{\max }=1.0 \mathrm{~mm}$, a similar trend cannot be observed. In contrast to the experiments of Nakao and Fityus (2008), Islam et al. (2011) and Alias et al. (2014), a higher maximum grain size of aggregate did not give rise to higher peak friction angle values, although no opposite trend in results can be observed.

Comparing the results of tests conducted using the two shearing techniques, in Table 7, the value of $\phi_{\text {pf }}$ of the first sequence of tests with repositioning and those without repositioning are quite close to each other: $\Delta \phi_{\text {pf }}$ has a maximum of $12 \%$, and a minimum of $-12 \%$. The values of $\Delta \phi_{\mathrm{pf}}$ in the case of comparing second shearing tests and tests without repositioning are also quite low (-8 to $12 \%$ ), with the exception of one of the four groups $\left(D_{\max }=0.5 \mathrm{~mm}, \sigma_{\mathrm{n}}=0.5-1.5 \mathrm{MPa}\right)$, in which the difference is higher, $44 \%$. The results of the third sequences show more significant differences (18-52\%) from the results of the other shearing technique, with the exception of one group $\left(\mathrm{D}_{\max }=1.0 \mathrm{~mm}: \sigma_{\mathrm{n}}=0.5-1.5 \mathrm{MPa}\right)$, in which that value remains $12 \%$. It has to be noted that, except in three cases, peak shear strength $\left(\tau_{\mathrm{p}}\right)$-applied normal stress $\left(\sigma_{\mathrm{n}}\right)$ data pairs based on modified shearing tests with repositioning are above the regression line of data pairs from tests without repositioning. Exceptions are the 3rd data pair of the first sequence in group of $\mathrm{D}_{\max }=0.5 \mathrm{~mm}: \sigma_{\mathrm{n}}=0.25-0.5 \mathrm{MPa}$ (Fig. 6a), the $1 \mathrm{st}$ and the 3rd data pairs of the first sequence in group of $\mathrm{D}_{\max }=1.0 \mathrm{~mm}: \sigma_{\mathrm{n}}=0.5-1.5 \mathrm{MPa}$ (Fig. 6d).

\section{Conclusion}

In this study, plaster mortar samples with two different maximum grain sizes of sand aggregate $\left(\mathrm{D}_{\max }=0.5 ; 1.0 \mathrm{~mm}\right)$ were examined by performing laboratory direct shear tests along discontinuities using two different multi-stage techniques (without repositioning and modified with repositioning); these were conducted in two different ranges of constant normal stresses $\left(\sigma_{\mathrm{n}}=0.25-0.5 \mathrm{MPa}\right.$ and $\left.0.5-1.5 \mathrm{MPa}\right)$. The surfaces of the samples were essentially similar, imitating a natural sandstone joint with low surface roughness $(\mathrm{JRC}=8)$. Furthermore, the various values of uniaxial compressive strength were quite similar: $\sigma_{\mathrm{c}}=16.04-26.84 \mathrm{MPa}\left(\mathrm{D}_{\max }=0.5 \mathrm{~mm}\right)$ and $\sigma_{\mathrm{c}}=18.84-24.15 \mathrm{MPa}\left(\mathrm{D}_{\max }=1.0 \mathrm{~mm}\right)$. Mohr-Coulomb $(\mathrm{M}-\mathrm{C})$ failure curves were calculated from the resulting peak shear strength-applied normal stress data pairs $\left(\tau_{p}-\sigma_{c}\right)$ using linear regression. Changes in the peak friction angle as a ratio of peak shear strength-applied normal stress $\left(\phi_{\mathrm{p}}\right)$, and as an M-C parameter $\left(\phi_{\mathrm{pf}}\right)$ were studied. 
(1) Although the Mohr-Coulomb linear failure criterion displays a good fit to experimental data pairs based on shear tests without repositioning both in the lower normal stress range $\left(\sigma_{\mathrm{n}}=0.25-0.5 \mathrm{MPa}\right)$ and in a higher normal stress range $\left(\sigma_{\mathrm{n}}=0.5-1.5 \mathrm{MPa}\right)$ for both grain sizes, the differences between the $\mathrm{M}-\mathrm{C}$ parameter $\phi_{\mathrm{pf}}$ in the different normal stress ranges are significant. Further studies are therefore needed in higher normal stress range $\sigma_{\mathrm{n}}=1.5-2.5 \mathrm{MPa}$ in order to analyse the possible changing trend of the $\phi_{\mathrm{pf}}$ values. Moreover, since these values are quite similar for both grain sizes in the lower normal stress range, while in the higher normal stress range the $\phi_{\text {pf }}$ associated with higher grain size had a higher value, further investigations on specimens with sand aggregate with maximum diameters of $2.0 \mathrm{~mm}$ and $4.0 \mathrm{~mm}$ are required in order to explore the differences between any possible changing trends in the value of $\phi_{\mathrm{pf}}$.

(2) Since the first sequence of the modified multi-stage shearing technique is equivalent to the employment of the single shearing technique, quite low differences between $\phi_{\text {pf }}$ of the first sequences of modified multi-stage shearing with repositioning and those of the multi-stage shearing without repositioning fell within the range of expectations both in different normal stress ranges and for different grain sizes. A shearing distance of $5 \mathrm{~mm}$ under different normal stresses during multi-stage tests without repositioning was found to be suitable for specimens $8.5 \mathrm{~cm}$ in length.

However, with an increasing number of shearing sequences, differences between the values of $\phi_{\text {pf }}$ on the basis of different techniques become higher, due to the fact that the value of $\phi_{\text {pf }}$ resulting from shear tests with repositioning changes significantly with the increasing number of shearing sequences and with a decreasing value of $c$. Although, as was the case of the results of shearing tests without repositioning, linear regression displays a good fit to $\tau_{p}-\sigma_{c}$ data pairs based on tests with repositioning, nonetheless, differences between $\mathrm{M}-\mathrm{C}$ parameters resulting from the two different techniques do not show a clear increasing or decreasing trend, even when grain sizes or normal stress ranges are changed. Finally, a significant difference between the results of the third shearing and the results of shearing without repositioning is always found.

In this study, laboratory direct shear tests were performed in a range of $\sigma_{\mathrm{c}} / \sigma_{\mathrm{n}}=11$ to 107 on plaster mortar replicas with relatively low joint roughness coefficient JRC $=8$. Under these conditions, different peak friction angles were obtained from repeated direct shear tests, and this remained true even in the same normal stress ranges. Further investigations with different conditions (e.g. materials with higher compressive strength $\sigma_{\mathrm{c}}$ ) are required to analyse the question of under which conditions the repeated shear tests might yield the same result, and even the ISRM has suggested multi-stage direct shear tests with repositioning could be employed.

Acknowledgements The research reported in this paper was supported by the 2018-2.1.13-TET-FR-201800012 .

Author contributions The authors applied the EC approach to the sequence of authors. NRB and AV designed the experiments, developed the materials, performed the tests, and wrote the manuscript. See https://doi.org/10.1371/journal.pbio.0050018 for further details. 
Funding Open access funding provided by Budapest University of Technology and Economics.

Open Access This article is licensed under a Creative Commons Attribution 4.0 International License, which permits use, sharing, adaptation, distribution and reproduction in any medium or format, as long as you give appropriate credit to the original author(s) and the source, provide a link to the Creative Commons licence, and indicate if changes were made. The images or other third party material in this article are included in the article's Creative Commons licence, unless indicated otherwise in a credit line to the material. If material is not included in the article's Creative Commons licence and your intended use is not permitted by statutory regulation or exceeds the permitted use, you will need to obtain permission directly from the copyright holder. To view a copy of this licence, visit http://creativecommons.org/licenses/by/4.0/.

\section{References}

Alias, R., Kasa, A., Taha, M.R.: Particle size effect on shear strength of granular materials in direct shear test. Int. J. Civ. Arch. Struct. Constr. Eng. 8(11), 733-736 (2014)

Barton, N.R.: A model study of rock-joint deformation. Eng. Geol. 7, 287-332 (1973)

Barton, N.: The shear strength of rock and rock joints. Int. J. Rock Mech. Min. Sci. Geomech. Abstr. 13, 255-279 (1976)

Barton, N., Bandis, S.: Effects of block size on the shear behaviour of jointed rock. In: The 23rd U.S Symposium on Rock Mechanics, Berkeley, California, pp. 739-760 (1982)

Barton, N.R., Choubey, V.: The shear strength of rock joints in theory and practice. Rock Mech. 10, 1-54 (1977)

Buocz, I., Rozgonyi-Boissinot, N., Török, Á.: Influence of discontinuity inclination on the shear strength of Mont Terri Opalinus claystones. Period. Polytech. Civ. Eng. 61, 447-453 (2017)

Grasselli, G., Egger, P.: Constitutive law for the shear strength of rock joints based on three-dimensional surface parameters. Int. J. Rock Mech. Min. Sci. 40, 25-40 (2003)

Haberfield, C.M., Seidel, J.P.: Some recent advances in the modelling of soft rock joints in direct shear. Geotech. Geol. Eng. 17, 177-195 (1999)

Islam, M.N., Siddika, A., Hossain, B., Rahman, A., Asad, A.: Effect of particle size on the shear strength behaviour of sand. Aust. Geomech. 46(3), 12 (2011)

Köppel, M., Martin, V., Roberts, J.E.: A stabilized Lagrange multiplier finite-element method for flow in porous media with fractures. Int. J. Geomath. 10, 7 (2019)

Kumar, R., Verma, A.K.: Anisotropic shear behaviour of rock joint replicas. Int. J. Rock Mech. Min. Sci. 90, 62-73 (2016)

Lee, Y.-K., Park, J.-W., Song, J.-J.: Model for the shear behaviour of rock joints under CNL and CNS conditions. Int. J. Rock Mech. Min. Sci. 70, 252-263 (2014)

Mentes, G.: Relationship between river bank stability and hydrological processes using in situ measurement data. Cent. Eur. Geol. 62(1), 83-99 (2019)

Miščević, P., Vlastelica, G.: Shear strength of weathered soft rock-proposal of test method additions. In: Vrkljan, I. (ed.) Proceedings of Regional Symposium of ISRM-EUROCK 2009, Rock Engineering in Difficult Conditions-Soft Rock and Karst, pp. 303-307 (2009)

Muralha, J., Grasselli, G., Tatone, B., Blümel, M., Chryssanthakis, P., Yujing, J.: ISRM suggested method for laboratory determination of the shear strength of rock joints: revised version. In: Ulusay, R. (ed.) The ISRM Suggested Methods for Rock Characterization, Testing and Monitoring: 2007-2014. Springer, Berlin (2015)

Nakao, T., Fityus, S.: Direct shear testing of a marginal material using a large shear box. Geotech. Test. J. 31(5), 393-403 (2008)

Niktabar, S.M.M., Rao, K.S., Shrivastava, A.K.: Effect of rock joint roughness on its cyclic shear behavior. J. Rock Mech. Geotech. Eng. 9, 1071-1084 (2017)

Patton, F.D.: Multiple modes of shear failure in rock. In: 1st International Society for Rock Mechanics (ISRM) Congress (1966)

Pirzada, M.A., Roshan, H., Sun, H., Oh, J., Andersen, M.S., Hedayat, A., Bahaaddini, M.: Effect of contact surface area on frictional behaviour of dry and saturated rock joints. J. Struct. Geol. 135, 104044 (2020) 
Sanei, M., Faramarzi, L., Fahimifar, A., Goli, S., Mehinrad, A., Rehmati, A.: Shear strength of discontinuities in sedimentary rock masses based on direct shear tests. Int. J. Rock Mech. Min. Sci. 75, 119-131 (2015)

Wang, J.J., Zhang, H., Tang, S., Liang, Y.: Effects of particle size distribution on shear strength of accumulation soil. J. Geotech. Geoenviron. Eng. 139(11), 1994-1997 (2013)

Yang, J., Rong, G., Hou, D., Peng, J., Zhou, C.: Experimental study on peak shear strength criterion for rock joints. Rock Mech. Rock Eng. 49, 821-835 (2016)

Zelasko, S., Krizek, R.J., Edil, T.B.: Shear behavior of sand as a function of grain characteristics. In: Proceedings of Conference on Soil Mechanics and Foundation Engineering, Istanbul, pp. 55-64 (1975)

Zhao, J.: Joint surface matching and shear strength part B: JRC-JMC shear strength criterion. Int. J. Rock Mech. Min. Sci. 34, 179-185 (1997)

Publisher's Note Springer Nature remains neutral with regard to jurisdictional claims in published maps and institutional affiliations. 